\title{
Article
}

\section{Regulation of Pkc1 Hyper-Phosphorylation by Genotoxic Stress}

\author{
Li Liu $^{1}$, Jiri Veis ${ }^{2,3}$, Wolfgang Reiter ${ }^{2,4}{ }^{(D}$, Edwin Motari ${ }^{1,+}{ }^{\text {, Catherine E. Costello }}{ }^{5} \mathbb{D}$, John C. Samuelson ${ }^{1,6}$, \\ Gustav Ammerer ${ }^{2}$ and David E. Levin 1,6,*
}

1 Department of Molecular and Cell Biology, Boston University Goldman School of Dental Medicine, Boston, MA 02118, USA; liul@bu.edu (L.L.); motari1@gmail.com (E.M.); jsamuels@bu.edu (J.C.S.)

2 Department of Biochemistry and Cell Biology, Max Perutz Labs, University of Vienna, 1030 Wien, Austria; jiri.veis@univie.ac.at (J.V.); reiterw6@univie.ac.at (W.R.); gustav.ammerer@univie.ac.at (G.A.)

3 Center for Medical Biochemistry, Max Perutz Laboratories, Medical University of Vienna, 1030 Wien, Austria

4 Mass Spectrometry Facility, Max Perutz Laboratories, University of Vienna, 1030 Wien, Austria

5 Department of Biochemistry, Center for Biomedical Mass Spectrometry, School of Medicine, Boston University, Boston, MA 02118, USA; cecmsms@bu.edu

6 Department of Microbiology, Boston University School of Medicine, Boston, MA 02118, USA

* Correspondence: delevin@bu.edu

† Current address: MilliporeSigma, Burlington, MA 01083, USA.

Citation: Liu, L.; Veis, J.; Reiter, W.; Motari, E.; Costello, C.E.; Samuelson, J.C.; Ammerer, G.; Levin, D.E.

Regulation of Pkc1

Hyper-Phosphorylation by Genotoxic Stress. J. Fungi 2021, 7, 874.

https://doi.org/10.3390/jof7100874

Academic Editors: María Molina and Humberto Martín

Received: 11 September 2021

Accepted: 13 October 2021

Published: 17 October 2021

Publisher's Note: MDPI stays neutral with regard to jurisdictional claims in published maps and institutional affiliations.

Copyright: (c) 2021 by the authors. Licensee MDPI, Basel, Switzerland. This article is an open access article distributed under the terms and conditions of the Creative Commons Attribution (CC BY) license (https:/ / creativecommons.org/licenses/by/ $4.0 /)$.

\begin{abstract}
The cell wall integrity (CWI) signaling pathway is best known for its roles in cell wall biogenesis. However, it is also thought to participate in the response to genotoxic stress. The stress-activated protein kinase Mpk1 (Slt2, is activated by DNA damaging agents through an intracellular mechanism that does not involve the activation of upstream components of the CWI pathway. Additional observations suggest that protein kinase $C$ ( $P k c 1)$, the top kinase in the CWI signaling cascade, also has a role in the response to genotoxic stress that is independent of its recognized function in the activation of Mpk1. Pkc1 undergoes hyper-phosphorylation specifically in response to genotoxic stress; we have found that this requires the DNA damage checkpoint kinases Mec1 (Mitosis Entry Checkpoint) and Tel1 (TELomere maintenance), but not their effector kinases. We demonstrate that the casein kinase 1 (CK1) ortholog, Hrr25 (HO and Radiation Repair), previously implicated in the DNA damage transcriptional response, associates with Pkc1 under conditions of genotoxic stress. We also found that the induced association of Hrr25 with Pkc1 requires Mec1 and Tel1, and that Hrr25 catalytic activity is required for Pkc1hyperphosphorylation, thereby delineating a pathway from the checkpoint kinases to Pkc1. We used SILAC mass spectrometry to identify three residues within Pkc1 the phosphorylation of which was stimulated by genotoxic stress. We mutated these residues as well as a collection of 13 phosphorylation sites within the regulatory domain of Pkc1 that fit the consensus for CK1 sites. Mutation of the $13 \mathrm{Pkc} 1$ phosphorylation sites blocked hyper-phosphorylation and diminished RNR3 (RiboNucleotide Reductase) basal expression and induction by genotoxic stress, suggesting that $\mathrm{Pkc1}$ plays a role in the DNA damage transcriptional response.
\end{abstract}

Keywords: Hrr25; Mec1; Tel1; Pkc1; hydroxyurea; UV irradiation

\section{Introduction}

The cell wall integrity (CWI) signaling pathway of the budding yeast Saccharomyces cerevisiae has been well characterized with regard to its regulation by cell wall stress [1-4]. This pathway regulates biosynthesis of cell wall polymers, organization of the actin cytoskeleton, exocytosis, and the protein kinase $\mathrm{C} 1$ ( $\mathrm{Pkc1}$ )-mediated stress-activated protein kinase (SAPK) cascade through activation of the small GTPase, Rho1. The SAPK cascade is a linear pathway comprised of Pkc1, a MEKK (Bck1), a pair of redundant MEKs (Mkk1/2) and a SAPK (Mpk1/Slt2). The activation of Mpk1, in response to cell wall stress or hyperactivation of upstream pathway components, drives transcription in support of cell wall biogenesis [5-9] through the SRF-like transcription factor RIm1 [10,11] and the cell cycle 
transcription factor SBF [12-15]. Moreover, loss-of-function mutants in the SAPK cascade display cell lysis defects that are suppressed by external osmotic support [2], highlighting the central role of this signaling pathway in the maintenance of cell wall integrity.

Although the CWI pathway is best understood for its essential role in maintaining the structural integrity of the cell wall during growth, morphogenesis, and in response to cell wall stressors, there is evidence that this pathway is also important for survival of genomic stress. Defects in any component of the CWI pathway, from the cell surface sensors to Mpk1, cause hyper-sensitivity to a variety of DNA damaging agents [16-20]. The CWI pathway SAPK Mpk1 is phosphorylated by the DNA damage checkpoint kinases Mec1 and Tel1 in response to treatment with methylmethane sulfonate (MMS) [21] or caffeine [22]. The Mec1 and Tel1 protein kinases are orthologs of mammalian ATR and ATM, respectively [23], and have overlapping but distinct functions in the maintenance of yeast genome integrity. Tel1 signals the presence of double-strand breaks specifically [24], whereas Mec1 signals the presence of a variety of DNA damage types, including double-strand breaks [25]. Mec1 and Tel1 phosphorylate and activate the checkpoint effector kinases Chk1 and Rad53, which mediate cell cycle arrest and gene expression in support of DNA repair [26-29].

In addition to phosphorylation of Mpk1, Soriano-Carot et al. [30] detected a DNA damage-induced hyper-phosphorylation of Pkc1. They suggested the existence of a reciprocal regulatory circuit in which Pkc1 was required to activate the DNA damage checkpoint and the DNA damage checkpoint kinase Tel1 was required for the phosphorylationinduced Pkc1 band-shift in response to DNA damage. However, we found that the DNA damage checkpoint is activated normally in $p k c 1 \Delta$ mutants from various strain backgrounds [31]. Additionally, there is a bifurcation of pathway outputs at Pkc1, first revealed as a 100-fold increase in mitotic recombination frequency in pkc1 mutants that is not observed in mutants of pathway components below Pkc1 [32]. This is significant because mitotic recombination is the principal mode of double-stranded break repair of DNA in yeast [33]. Moreover, Pkc1 phosphorylates and activates CTP synthetase directly [34], revealing a role in nucleotide metabolism.

Finally, Mpk1 is activated by genotoxic stress through a pathway that does not require the activation of Pkc1 or the other protein kinases that function above Mpk1, but involves ubiquitination and degradation of Msg5, the protein phosphatase that normally maintains Mpk1 in a low activity state [31,35]. Intriguingly, Mpk1 activated in response to genotoxic stress does not drive cell wall stress transcription, suggesting that its activation in this context has a different function. These observations have led to the proposal that Pkc1 plays important roles in the response to genotoxic stress that are separate from its function in the activation of the CWI SAPK cascade [30], but these roles have not been elucidated. We hypothesize that the CWI pathway plays multiple unrecognized roles in the response to DNA damage- some driven by Mpk1, others by another pathway branch from Pkc1. In this study, we establish the pathway through which Pkc1 is hyper-phosphorylated in response to DNA damage and identify several sites within the Pkc1 regulatory domain whose phosphorylation is stimulated under conditions of genotoxic stress. Mutation of these sites impacts DNA damage-regulated gene expression.

\section{Materials and Methods}

\subsection{Strains, Growth Conditions, and Transformations}

The S. cerevisiae strains used in this study were derived from the EG123 background [36], the RDK2669 background (M. Smolka), the W303 background (J.C. Igual), or the Research Genetics background BY4742 (Research Genetics, Inc.; Huntsville, AL, USA) and are listed in Table 1. 
Table 1. Yeast strains used in this study.

\begin{tabular}{|c|c|c|}
\hline Strain & Relevant Genotype & Source or Reference \\
\hline DL100 & MATa EG123 ura3-52 leu2-3,112 trp1-1 his4 can1 ${ }^{r}$ & [36] \\
\hline DL376 & MATa EG123 ura3-52 leu2-3,112 trp1-1 his4 pkc1 & David Levin \\
\hline DL1021 & MATa SEY6210 leu2-3,112 ura3-52 his3-200 trp1-901 ede2-101 pkc1ه::HIS3 suc2-9 (GPY1115) & Gerhard Paravicini \\
\hline DL2772 & MAT $\alpha$ S288c (BY4742) his3 leu2 lys2 ura3 & Research Genetics \\
\hline DL3950 & MAT $\alpha$ MBS62 sml1 $\triangle:: T R P 1$ & Marcus Smolka \\
\hline DL3951 & MAT $\alpha$ MBS103 sml1 $\triangle:: T R P 1$ tel1 $\triangle:: U R A 3$ & Marcus Smolka \\
\hline DL3952 & MAT $\alpha$ MBS104 sml1 $:: T R P 1 ~ m e c 1 \Delta:: K a n M X$ & Marcus Smolka \\
\hline DL3953 & 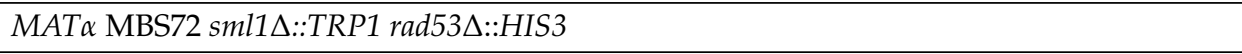 & Marcus Smolka \\
\hline DL3954 & 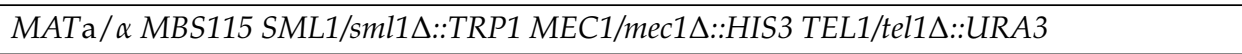 & Marcus Smolka \\
\hline DL4206 & MATa W303 ade2 trp1 leu2 his3 ura3 can1 & Juan Carlos Igual \\
\hline DL4277 & 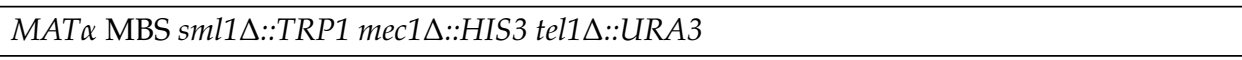 & This study \\
\hline DL4286 & 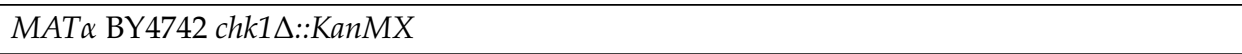 & Research Genetics \\
\hline DL4290 & $\begin{array}{l}\text { MATa ura3-52 lys2-801 ade2-101 trp1- } \Delta 63 \text { his3- } \Delta 200 \text { leu2- } \Delta 1 \text { hrr25 }:: \text { loxP-kanMX-loxP } \\
\text { pGAL1-3HA-HRR25degron }(\mathrm{KKY} 387)\end{array}$ & [37] \\
\hline DL4503 & 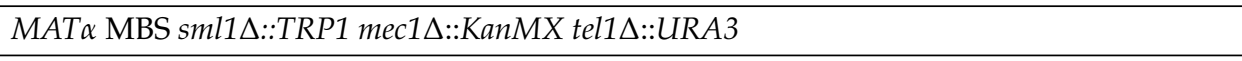 & This study \\
\hline DL4515 & MATa W303 hrr25 & This study \\
\hline DL4527 & MATa W303 hrr25 ::HPHMX4 (pHRR25-HA; p3545, HIS3 CEN) & This study \\
\hline DL4528 & MATa W303 hrr25 & This study \\
\hline DL4541 & 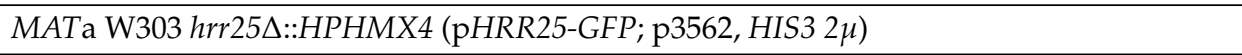 & This study \\
\hline DL4542 & MATa W303 hrr25 & This study \\
\hline DL4555 & MATa W303 hrr25 & This study \\
\hline DL4556 & MATa W303 hrr25 & This study \\
\hline JV826 & MATa BY4741 PKC1-HTBeaq::NatMX & This study \\
\hline
\end{tabular}

Yeast cell cultures were grown in YPD (1\% Bacto yeast extract, 2\% Bacto Peptone, $2 \%$ glucose $)$ or minimal selective medium, $\mathrm{SD}(0.67 \%$ Yeast nitrogen base, $2 \%$ glucose $)$ supplemented with the appropriate nutrients to select for plasmids, which are listed in Table 2. Yeast cells were transformed according to Geitz et al. [38]. Sorbitol (0.5 M) was used to prevent cell lysis for pkc1 $\Delta$ strains. Cell wall stress was induced by treatment with calcofluor white (CFW, $40 \mu \mathrm{g} / \mathrm{mL}$; Millipore Sigma, Burlington, MA), or by heat shock at $39{ }^{\circ} \mathrm{C}$. Genotoxic stress was induced by treatment with hydroxyurea (HU; $250 \mathrm{mM}$, except where indicated otherwise; Fisher Scientific, Waltham, MA) or ultraviolet light (UV; $150 \mathrm{~J} / \mathrm{m}^{2}$ for Pkc1 band-shift, or $250 \mathrm{~J} / \mathrm{m}^{2}$ for viability assay). UV irradiation was carried out using an Analytik Jena UVP Crosslinker (Fisher Scientific). Cultures for viability tests were pelleted and resuspended in phosphate-buffered saline (PBS), dispersed on the surface of an empty petri dish for irradiation prior to dilution and plating. Cultures for Pkc1 band-shift were incubated in YPD for an additional $2 \mathrm{~h}$ for recovery after irradiation. To inhibit Hrr25 catalytic activity, $5 \mu \mathrm{M}$ or $10 \mu \mathrm{M}$ of PP1 analog IV, PP1 analog II (1NM PP1), or PP1 analog (Millipore Sigma) were used in agar plates. For Hrr25 inhibition in culture, PP1 analog IV $(20 \mu \mathrm{M})$ was added to cultures at the time of addition of HU and incubated for $4 \mathrm{~h}$. 
Table 2. Plasmids used in this study.

\begin{tabular}{|c|c|c|}
\hline Plasmid & Description & Source or Reference \\
\hline p117 & pRS313 & [39] \\
\hline p118 & pRS314 & [39] \\
\hline p119 & pRS315 & [39] \\
\hline p120 & YEp351 & {$[40]$} \\
\hline p813 & YEp351-PKC1-HA & David Levin \\
\hline p1105 & pRS425 & [39] \\
\hline p1202 & pRS425-GFP & David Levin \\
\hline p2062 & pVDG7 PKC1-GFP & [41] \\
\hline p2454 & pRS413 & [39] \\
\hline p2947 & $\mathrm{p} R N R 3-l a c Z$ & Stephen Elledge \\
\hline p3064 & pAG32-RGC2 & {$[42]$} \\
\hline p3149 & pRS425-3HA-ADH1 ${ }^{T}$ & {$[42]$} \\
\hline p3357 & pUG36-HRR25-GFP & Martha Cyert \\
\hline p3358 & pUG36-GFP & Martha Cyert \\
\hline p3484 & pRS425-HRR25-HA & This study \\
\hline p3504 & pRS313-3HA-ADH1 ${ }^{T}$ & This study \\
\hline p3517 & YEp351-pkc1-S577A-HA & This study \\
\hline p3521 & YEp351-pkc1-S577A, S626A-HA & This study \\
\hline p3522 & YEp351-pkc1-S577A, T626A, T753A-HA & This study \\
\hline p3523 & YEp351-pkc1-S577A, T626A, T753A, S804A-HA & This study \\
\hline p3525 & pRS315-HRR25-HA & This study \\
\hline p3538 & pRS425-hrr25- $\triangle 404-H A$ & This study \\
\hline p3544 & pRS423-3HA-ADH1 ${ }^{T}$ & This study \\
\hline p3545 & pRS313-HRR25-HA & This study \\
\hline p3546 & pRS313-hrr25- $\triangle 404-H A$ & This study \\
\hline p3547 & pRS423-HRR25-HA & This study \\
\hline p3550 & pRS313-hrr25-I82A-HA & This study \\
\hline p3552 & pRS423-hrr25-I82A-HA & This study \\
\hline p3553 & pRS423-hrr25-I82G-HA & This study \\
\hline p3560 & pRS423-GFP & This study \\
\hline p3562 & pRS423-HRR25-GFP & This study \\
\hline p3567 & pRS423-hrr25- $\triangle 404-G F P$ & This study \\
\hline p3570 & pRS313-hrr25-T453A-HA & This study \\
\hline p3572 & pRS313-hrr25-T453A, S405A-HA & This study \\
\hline p3574 & YEp351-pkc1-S577A, T626A, T753A, S761A, S804A-HA & This study \\
\hline p3576 & pRS313-hrr25-T453A, S405A, S438A-HA & This study \\
\hline p3597 & YEp351-pkc1-S577A, T626A, T753A, S761A, S772A, S804A-HA & This study \\
\hline p3603 & YEp351-pkc1-S577A, T626A, S686A, T753A, S761A, S772A, S804A-HA & This study \\
\hline p3604 & YEp351-pkc1-S577A, T626A, S686A, S750A, T753A, S761A, S772A, S804A-HA & This study \\
\hline p3605 & YEp351-pkc1-S152A, S577A, T626A, S686A, S750A, T753A, S761A, S772A, S804A-HA & This study \\
\hline p3606 & $\begin{array}{l}\text { YEp351-pkc1-S152A, S577A, T626A, S657A, S686A, S750A, T753A, S761A, S772A, } \\
\text { S804A-HA }\end{array}$ & This study \\
\hline p3608 & $\begin{array}{l}\text { YEp351-pkc1-S152A, S577A, T626A, S657A, S686A, S750A, T753A, S761A, S772A, S781A, } \\
\text { S804A-HA }\end{array}$ & This study \\
\hline
\end{tabular}


Table 2. Cont.

\begin{tabular}{|c|c|c|}
\hline Plasmid & Description & Source or Reference \\
\hline p3610 & $\begin{array}{l}\text { YEp351-pkc1-S75A, S152A, S577A, T626A, S657A, S686A, S750A, T753A, S761A, S772A, } \\
\text { S781A, S804A-HA }\end{array}$ & This study \\
\hline p3612 & $\begin{array}{l}\text { YEp351-pkc1-S75A, S152A, S577A, T626A, S657A, S686A, S750A, T753A, S761A, S772A, } \\
\text { S781A, S797A, S804A-HA (S/T13A) }\end{array}$ & This study \\
\hline p3617 & YEp351-pkc1-S2A-HA & This study \\
\hline p3618 & YEp351-pkc1-S2A, S657A-HA & This study \\
\hline p3619 & YEp351-pkc1-S2A, S657A, S577A-HA (S3A) & This study \\
\hline p3623 & pRS314-PKC1-HA & This study \\
\hline p3624 & pRS314- $p k c 1-S 2 A, S 657 A, S 577 A-H A(\mathrm{~S} 3 \mathrm{~A})$ & This study \\
\hline p3625 & $\begin{array}{l}\text { pRS314-pkc1-S75A, S152A, S577A, T626A, S657A, S686A, S750A, T753A, S761A, S772A, } \\
\text { S781A, S797A, S804A-HA (S/T13A) }\end{array}$ & This study \\
\hline pWR268 & pFA6a-integrative HTBeaq tag, NatMX & {$[43]$} \\
\hline
\end{tabular}

\subsection{Chromosomal Deletions and Strain Construction}

A sml1 $\triangle:: T R P 1$ mec1 $\triangle:: H I S 3$ tel1 $\triangle::$ URA3 strain (DL4277) was generated as a meiotic segregant of DL3954 (MATa/ $\alpha$ MBS115 SML1/sml1 $::: T R P 1$ MEC1/mec1 $:: H I S 3$ TEL1/tel1 $\triangle:: U R A 3)$. An sml1 $\triangle:: T R P 1$ mec1 $1:: K a n M X$ tel1 $\triangle:: U R A 3$ strain (DL4503) was created by homologous recombination of mec1 $\triangle:: K a n M X$ at the MEC1 locus in an sml1 $\triangle:: T R P 1$ tel1 $\triangle::$ URA3 strain (DL3951). The mec1 $\triangle:: K a n M X$ allele was amplified by PCR from genomic DNA of yeast strain (DL3952) using Phusion high-fidelity DNA polymerase (Thermo Fisher Scientific, San Jose, CA). Transformants were selected for antibiotic G418 resistance and validated by genomic PCR across both integration junction sites. Endogenous tagging of Pkc1 with HTBeaq [43] was achieved by transformation of BY4741 with HB-tagging cassettes amplified from plasmid pWR268 [43], resulting in yeast strain JV826.

Plasmid-borne "gatekeeper" alleles of HRR25 were tested for function initially in an hrr25 $\Delta$ strain maintained with a plasmid-borne, GAL1-controlled HRR25 ${ }^{\text {degron }}$ (DL4290) [37], which is viable only in galactose-containing medium. Later experiments with these mutant alleles were conducted in an hrr $25 \Delta$ strain without the HRR $25^{\text {degron }}$. To create hrr25 $\triangle:: H P H M X 4$ in W303 (DL4515), a plasmid bearing HRR25-HA (p3484; pRS425-HRR25HA) was first introduced into DL4206 (MATa W303 ade2 trp1 leu2 his3 ura3 can1). The HPHMX4 gene was amplified by PCR from plasmid p3064 (pAG32-RGC2) using primers with extensions homologous to the $5^{\prime}$ and $3^{\prime}$ ends of HRR25 and used to transform DL4206 pRS425-HRR25-HA to hygromycin B resistance. Gene replacement was validated by PCR analysis across both integration junctions. The plasmid-borne HRR25 in DL4515 was replaced with other alleles of HRR 25 carried on pRS313 or pRS423 using plasmid shuffle.

\subsection{Plasmid Construction and Mutagenesis}

The HRR25 gene was epitope-tagged on its C-terminus with 3xHA and expressed from its natural promoter. The promoter region of HRR25 (from position -979) and its entire coding sequence was amplified from genomic yeast DNA (DL2772) by high-fidelity PCR polymerase (Phusion) using primers designed with a HindIII site (upstream) and a NotI site (downstream), and subcloned into pRS425-3HA-ADH1 ${ }^{T}$ (p3149) to generate pRS425HRR25-HA (p3484). To create pRS425-hrr25- $4404-H A$ (p3538), the promoter region of $H R R 25$ (from position -979) and its C-terminally truncated coding sequence was amplified from pRS425-HRR25-HA (p3484) by high-fidelity PCR polymerase (Phusion) using primers designed with a HindIII site (upstream) and a NotI site (downstream) and subcloned into pRS425-3HA-ADH1 ${ }^{T}$ (p3149).

To express HA-tagged HRR25 from HIS3-marked plasmids pRS313-3HA-ADH1 ${ }^{T}$ (p3504) and pRS423-3HA-ADH1 ${ }^{T}$ (p3544), first required subcloning of the $3 H A-A D H 1^{T}$ sequence from pRS425-3HA-ADH1 ${ }^{T}$ (p3149) into pRS313 or pRS423 [39] at SmaI and 
SacI sites. Plasmid pRS313-HRR25-HA (p3545) was next created by subcloning a Sal1Not1 fragment containing the promoter region of HRR25 (from position -979) and its entire coding sequence from pRS425-HRR25-HA (p3484) into pRS313-3HA-ADH1 ${ }^{T}$ (p3504). Plasmid pRS313-hrr25- $\triangle 404-H A$ (p3546) was created similarly. Plasmid pRS423-HRR25$H A$ (p3547) was generated by subcloning the Sal1-Not1 fragment containing HRR25 into pRS423-3HA-ADH1 ${ }^{T}$ (p3544).

The HRR25 gene was also epitope-tagged on its C-terminus with GFP and expressed from its natural promoter. A PCR fragment containing the GFP coding sequence was amplified from pRS425-GFP (p1202) with primers designed with Sma1 and Not1 sites (upstream) and a SacII site (downstream) and cloned into pRS423 to create GFP-tagging vector pRS423-GFP (p3560). An Apa1-Not1 fragment containing the promoter region of HRR25 (from position -979) and its entire coding sequence digested from pRS423-HRR25-HA (p3547) was subcloned into pRS423-GFP (p3560) at the Apa1-Not1 sites to generate pRS423HRR25-GFP (p3562). Plasmid pRS423-hrr25- $\triangle 404-G F P$ (p3567) was similarly created from pRS313-hrr25- $\triangle 404-H A$ (p3546).

Point mutations in PKC1 were constructed initially in high copy plasmid YEp351PKC1-HA (p813) for use in band-shift assays. However, for phenotypic analyses, we expressed mutant alleles of $P K C 1-H A$ from a centromeric plasmid. To create pRS314-PKC1$H A, p k c 1-3 A-H A$, and $p k c 1-S / T 13 A-H A, P K C 1-H A$ (from position -950) with its $3^{\prime}$ region (640 bp) were PCR amplified from YEp351-PKC1-HA (p813), YEp351-pkc1-S3A-HA (p3619) or YEp351-pkc1-S/T13A-HA (p3612), respectively, by PrimeSTAR, Max DNA Polymerase (Takara Bio USA, Mountainview, CA) using primers designed with a Sall site (upstream) and with a SacII site (downstream) and cloned into pRS314 (p118).

All point mutations in HRR25 or PKC1 were created using QuickChange or QuikChange Lightning Site-Directed Mutagenesis Kits (Agilent Technologies, Santa Clara) according to manufacturer's instructions. All DNA sequences derived from PCR mutagenesis were confirmed by sequence across the entire gene.

\subsection{Protein Extraction}

Protein extraction was carried out as described previously for co-immunoprecipitation [44], or using the rapid boiling method [45] for direct immunoblot experiments.

\section{5. $\beta$-galactosidase Measurements}

Measurements of $\beta$-galactosidase activity from RNR3-lacZ (p2947) expression experiments were conducted in triplicate and carried out as described in Zhao et al. [46].

\subsection{Dephosphorylation Assay}

Protein extracts were prepared from sml1 (DL3950) cells carrying PKC1-HA (p813), treated with $250 \mathrm{mM}$ HU or untreated, by bead-beating in lysis buffer (10\% glycerol, $20 \mathrm{mM}$ Hepes pH 7.5, $150 \mathrm{mM} \mathrm{NaCI}, 0.5 \%$ triton X-100 and Mini protease inhibitor cocktail (Milipore Sigma), without phosphatase inhibitors, followed by centrifugation. The dephosphorylation reactions were performed using Lambda protein phosphatase (New England Biolabs, Ipswich, MA) according to manufacturer's protocol. Briefly, $10 \mu \mathrm{g}$ of protein extract was incubated with 400 units of Lambda protein phosphatase in Lambda protein phosphatase buffer for $30 \mathrm{~min}$ at $30^{\circ} \mathrm{C}$. Phosphatase reactions were stopped by adding an equal volume of $2 \times$ SDS sample buffer and the resulting samples were boiled for $3 \mathrm{~min}$ prior to SDS-PAGE and immunoblot analysis.

\subsection{Co-Immunoprecipitation}

To detect association of Pkc1 with Hrr25 in wild-type cells, a plasmid expressing Pkc1-HA under the control of its own promoter (p813) was co-transformed with plasmids expressing either GFP-Hrr25 (p3357) or GFP alone (p3358) into DL100. Transformants were grown to mid-log phase in selective medium and starved for methionine for two hours to induce expression of GFP-Hrr25 or GFP, which were expressed under the control of 
the MET25 promoter. Cultures were then treated with $250 \mathrm{mM} \mathrm{HU}$ for $4 \mathrm{~h}$. To test the effect of MEC1 and TEL1 loss on the association of Pkc1 with Hrr25, a plasmid expressing Hrr25-GFP under the control of its own promoter (p3562) was co-transformed with p813 into strains DL3950 (sml1 $)$ ) and DL4503 (sml1 $\Delta$ mec1 $\Delta$ tel1 $\Delta)$. To test the association of Pkc1-HA with truncated Hrr25 (Hrr25- $4404-G F P)$, plasmid p813 was transformed into strains bearing a chromosomal deletion of HRR25 complemented by plasmids expressing either Hrr25-GFP (DL4541) or Hrr25- $\triangle 404-G F P$ (DL4542). Transformants were grown to mid-log phase in selective medium and treated with $250 \mathrm{mM} \mathrm{HU}$ for $4 \mathrm{~h}$. Protein extracts were made as described previously [44]. Extracts (100 $\mu \mathrm{g}$ of protein) were incubated with $10 \mu \mathrm{L}$ of GFP-trap agarose beads (Chromotek, Munich, Germany) at $4{ }^{\circ} \mathrm{C}$ for $2 \mathrm{~h}$ and the samples were washed with IP buffer (50 mM Tris- $\mathrm{HCl}, \mathrm{pH} 7.5,150 \mathrm{mM} \mathrm{NaCl}, 0.5 \%$ Triton) three times and boiled in SDS-PAGE buffer.

\subsection{SDS-PAGE Electrophoresis and Immunoblot Analysis}

Proteins were separated by SDS-PAGE (10\% or 4-20\% Mini-PROTEAN TGX gels, BioRad, Hercules, CA, USA) followed by immunoblot analysis using mouse monoclonal $\alpha$ HA (BioLegend, San Diego, CA, USA) or $\alpha$-GFP (Millipore Sigma) at a dilution of 1:10,000 and polyclonal rabbit $\alpha$-Rad53 (Abcam) antibodies at a dilution of 1:2000 to detect Pkc1-HA or-GFP, Hrr25-HA or -GFP and Rad53, respectively. Secondary goat anti-mouse (Jackson ImmunoResearch, Westgrove, PA, USA) and donkey anti-rabbit (GE Healthcare, Chicago, IL, USA) antibodies were used at a dilution of 1:10,000. SDS-PAGE gels used to detect Pkc1 band-shifts were $10 \%$ and those used for Pkc1 association with Hrr25 were 4-20\%.

\subsection{Mass Spectrometric Analysis of Pkc1 Co-Immunoprecipitates}

Pkc1-GFP was expressed from plasmid p2062 (gift of M. Cyert) in strain DL100 and isolated using GFP-trap agarose. Pkc1-GFP immunoprecipitates were run on SDS-PAGE gels prior to in-gel digestion of the contents of the entire lane with trypsin. After desalting, LC-MS/MS was performed using a nanoAcquity ultra-performance liquid chromatography (UPLC) capillary system (Waters Corp., Milford, MA, USA), coupled to an LTQ-Orbitrap hybrid mass spectrometer (Thermo Fisher Scientific) equipped with a TriVersa NanoMate ion source (Advion, Ithaca, NY, USA). Sample concentration and desalting were performed online using a nanoAcquity UPLC trapping column $(180 \mu \mathrm{m}$ by $20 \mathrm{~mm}$; packed with $5-\mu \mathrm{m}$, 100-Å-pore-size Symmetry $C_{18}$ material; Waters Corp.) at a flow rate of $15 \mu \mathrm{L} / \mathrm{min}$ for $1 \mathrm{~min}$. Separation was accomplished on a nanoAcquity UPLC capillary column $(100 \mu \mathrm{m}$ by $100 \mathrm{~mm}$; packed with $1.7-\mu \mathrm{m}, 130$ - $\AA$-pore-size bridged ethyl hybrid [BEH] $\mathrm{C}_{18}$ material; Waters Corp.). A linear gradient of $\mathrm{A}$ and $\mathrm{B}$ buffers (buffer $\mathrm{A}, 3 \% \mathrm{ACN}-0.1 \%$ formic acid [FA]; buffer B, 97\% ACN-0.1\% FA) from 7\% to $45 \%$ buffer B over $124 \mathrm{~min}$ was used at a flow rate of $0.5 \mu \mathrm{L} / \mathrm{min}$ to elute peptides into the mass spectrometer. Columns were washed and re-equilibrated between LC-MS/MS experiments. Electrospray ionization was carried out at $1.7 \mathrm{kV}$ using the NanoMate, with the LTQ heated capillary set to $150{ }^{\circ} \mathrm{C}$.

Mass spectra were acquired in the orbitrap mass analyzer in the positive-ion mode over the range of $m / z 300$ to 2000 at a resolution of $60,000 @ m / z 400$. Mass accuracy after internal calibration was within 4 ppm. Simultaneously, tandem MS spectra were acquired using the LTQ for the five most abundant, multiply charged species in the mass spectrum with signal intensities of $>8000$ signal/noise levels. With MS/MS collision energies set at $35 \%$, and helium used as the collision gas, MS/MS spectra were acquired over a range of $m / z$ values dependent on the precursor ion. Dynamic exclusion was set such that MS/MS data for each species were acquired a maximum of twice. All spectra were recorded in profile mode for further processing and analysis. Xcalibur software was used for MS and MS/MS data analysis, while peptide and protein assignments were conducted using Mascot to search against the ScerevisiaeOrfTrans database. 


\subsection{Mass Spectrometric Analysis of Pkc1 Phospho-Sites}

Histidine-biotin tandem affinity purifications of Pkc1-HTBeaq were based on methods described elsewhere [43], with modifications below. Stable isotope labeling using amino acids in cell culture (SILAC) [47] was achieved as described previously [43]. Cells expressing Pkc1 C-terminally tagged with a HTBeaq tag [43] were grown to mid-logarithmic phase $\left(\mathrm{OD}_{600 \mathrm{~nm}}=2.0\right)$, treated with $200 \mathrm{mM} \mathrm{HU}$ for $4 \mathrm{~h}$, harvested by filtration, and rapidly deep frozen in liquid $\mathrm{N}_{2}$. In-solution digestion with trypsin and enrichment of phosphorylated peptides using $\mathrm{TiO}_{2}$ was performed as described previously [43].

For these mass spectrometry analyses, a Q Exactive HF Orbitrap (Thermo Fisher Scientific) mass spectrometer was used with the following settings: Peptides were separated applying an increasing organic solvent (acetonitrile) gradient from $2.5 \%$ to $40 \%$ in $0.1 \%$ formic acid over 60 (YPD) or 120 (SILAC) minutes at a flow rate of $275 \mathrm{nl} / \mathrm{min}$. MS1 resolution was set to 70,000 @ m/z 200, AGC $3 \times 10^{6}$. MS2 resolution was set to $17,500 @ \mathrm{~m} / z 200$, AGC $1 \times 10^{5}, 500 \mathrm{~ms}$ max. ion injection time (IIT). The mass spectrometer was configured to pick the twelve most abundant precursor ions for data-dependent MS2 scans, applying HCD for fragmentation with a normalized collision energy (NCE) of 27. Dynamic exclusion time was set to $30 \mathrm{~s}$. MS raw files were processed using MaxQuant (Max Planck Institute of Biochemistry, Munich) [48] software version 1.5.2.8 using standard settings, except for the following modifications. Spectra were searched against the Saccharomyces Genome Database (http:/ / www.yeastgenome.org/ accessed on 8 October 2015) containing 6717 entries (3 February 2011), including a list of 248 common laboratory contaminants as well as reversed versions of all sequences. The enzyme specificity was set to trypsin. A maximum of two missed cleavages was allowed. Phosphorylation of serine, threonine, and tyrosine residues, oxidation of methionine, and deamidation of asparagine were set as variable modifications. For stable isotope labeling using amino acids in cell culture (SILAC)-labeled samples, Lys6 and Arg6 were additionally selected. Carbamidomethylation of cysteine was searched as a fixed modification. A maximum of five modifications per peptide was allowed. The false discovery rate for peptide, protein, and site identification was set to $1 \%$. All files were searched together. Minimum delta score for modified peptides was set to 6 . The MS phospho-proteomics data have been deposited at the zenodo repository (https://zenodo.org/ accessed on 10 September 2021) and can be accessed via https:/ / doi.org/10.5281/zenodo.5552273.

\subsection{Notes on Reproducibility}

All immunoblots, and co-IPs, were reproduced at least once in independent experiments with representative images shown.

\section{Results and Discussion}

Pkc1 undergoes a phosphorylation-induced band-shift in response to DNA damage [30]. We found that the Pkc1 band-shift was induced specifically in response to DNA damage by alkylating agent methylmethane sulfonate (MMS), by dNTP depletion by hydroxyurea (HU) treatment, or by UV irradiation, but not in response to cell wall stress treatments calcofluor white (CFW) or elevated growth temperature (Figure 1a). We confirmed that this band-shift results from hyper-phosphorylation by treatment with Lambda protein phosphatase (Figure 1b). We also found that it is dependent on the partially redundant DNA damage checkpoint kinases Mec1 and Tel1 (Figure 1c). This is in contrast to the findings of Soriano-Carot, et al. [30], who found that Tel1 was uniquely responsible for the Pkc1 band-shift. In any case, we found that both of the known effector kinase targets of the checkpoint kinases, Rad53 and Chk1 [49,50], were dispensable for the Pkc1 band-shift (Figure 1d). These results suggest that Mec1 and Tel1 either phosphorylate Pkc1 directly, or act on another protein kinase that phosphorylates Pkc1. Thus, the DNA damage checkpoint kinases, Mec1 and Tel1, regulate hyper-phosphorylation of $\mathrm{Pkc1}$ in response to genotoxic stress. 


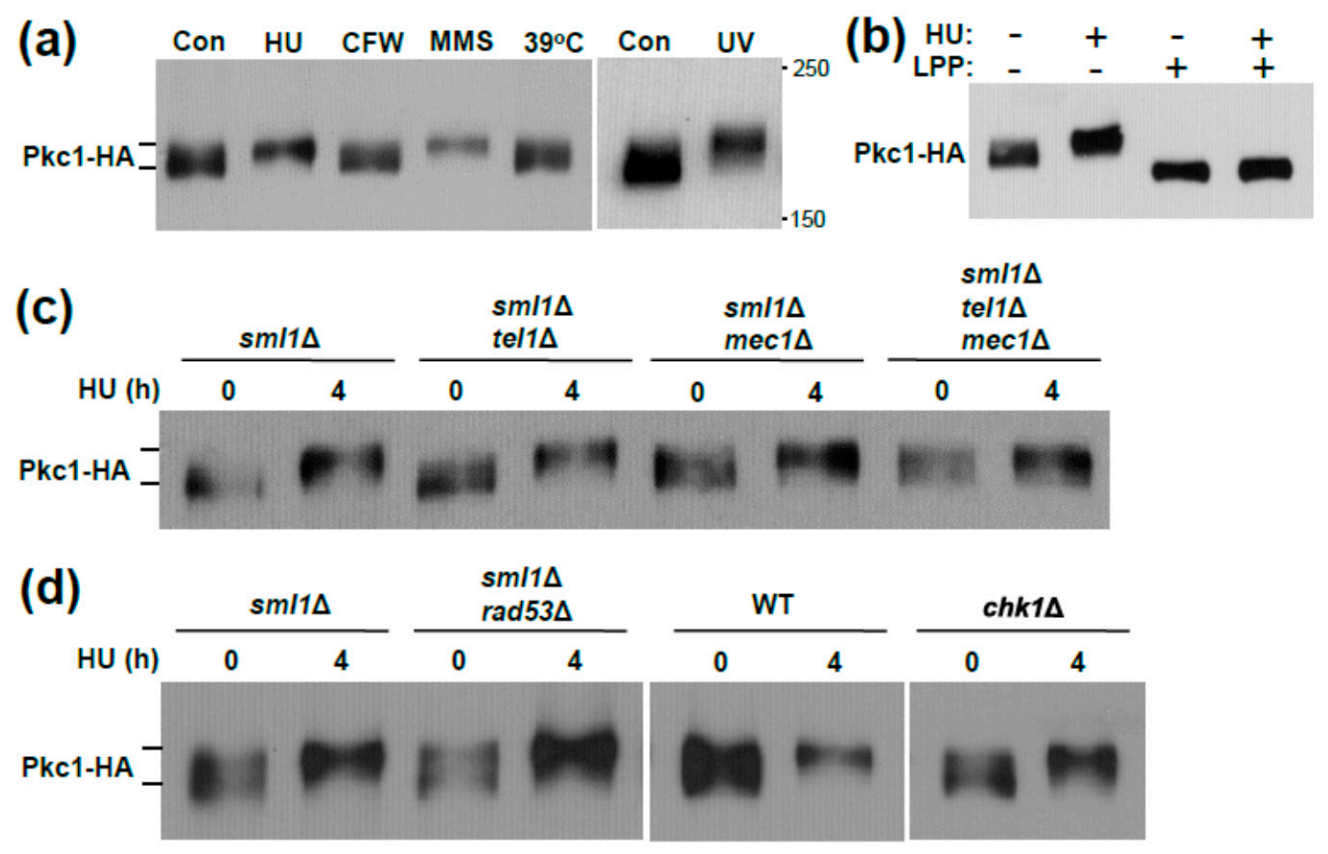

Figure 1. A phosphorylation band-shift in $P k c 1$ requires the $M E C 1$ and TEL1 DNA damage checkpoint genes. (a) A Pkc1 band-shift is induced specifically by genotoxic stressors. Wild-type cells (DL3950; sml1 $\Delta$ ) expressing Pkc1-HA (from p813) were exposed to genotoxic stress (250 mM HU for $4 \mathrm{~h}, 0.04 \%$ MMS for $2 \mathrm{~h}$, or $150 \mathrm{~J} / \mathrm{m}^{2} \mathrm{UV}$ with a $2 \mathrm{~h}$ recovery period), cell wall stress $(40 \mu \mathrm{g} / \mathrm{mL} \mathrm{CFW}$ for $1 \mathrm{~h}$, or heat shock at $39^{\circ} \mathrm{C}$ for $1 \mathrm{~h}$ ), or untreated (Con). Extracts were subjected to SDS-PAGE and immunoblot analysis for Pkc1-HA; (b) Phosphorylation is responsible for the HU-induced band-shift. Wild-type cells (DL3950) expressing Pkc1-HA were either treated with HU as above, or untreated. Extracts were treated with Lambda protein phosphatase (LPP), as described in Methods, prior to immunoblot analysis; (c,d) The HU-induced Pkc1 band-shift requires MEC1 and TEL1, but not the checkpoint genes that they regulate (RAD53 or CHK1). Cultures were treated with HU as above prior

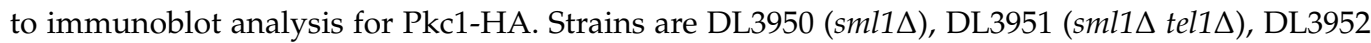

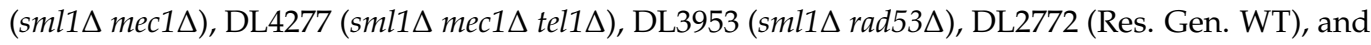
DL4286 (Res. Gen. chk1 $\Delta$ ). The sml1 $\Delta$ mutation is required to suppress the lethality of the mec1 $\Delta$ and rad53 $\Delta$ mutations.

\subsection{Genotoxic Stress Induces Hrr25 Association with Pkc1}

Next, we took a proteomics approach to identify protein kinases that associate with Pkc1 in response to HU-induced genotoxic stress. Cells expressing Pkc1-GFP were treated with $250 \mathrm{mM} \mathrm{HU}$ for $4 \mathrm{~h}$, or were untreated, and Pkc1-GFP was immunoprecipitated from extracts and subjected to mass spectrometric (MS) analysis to identify co-precipitating proteins. Proteins that were found associated with Pkc1 only after HU treatment, or only without HU treatment are presented in Supplemental Tables S1 and S2, respectively. Although numerous non-specific associations were detected in both the untreated and treated samples, a minor signal from the DNA damage and repair kinase Hrr25 ( $\mathrm{HO}$ and radiation repair) [51] was detected only in the HU-treated sample. HRR25 encodes an isoform of casein kinase 1 (CK1) that has been implicated in the repair of DNA double strand breaks [51] and is required for the transcriptional induction of the ribonucleotide reductase genes RNR2 and RNR3 in response to DNA damage [52]. Many physical interactors have been identified for Pkc1, but Hrr25 is not among them (Saccharomyces Genome Database). Therefore, we validated the physical association between Pkc1 and Hrr25 by co-immunoprecipitation (co-IP). Not only did we detect a stable interaction between Pkc1HA and Hrr25-GFP, but the interaction was reproducibly induced 5-10-fold in response to treatment with HU (Figure 2a). We detected no non-specific binding of Pkc1-HA to either GFP alone (Figure 2a), or to the GFP-trap beads (Supplemental Figure S1). Hrr25 
was recruited similarly to $\mathrm{Pkc1}$ in response to ultraviolet (UV) light exposure (Figure 2b), suggesting that this is part of the generalized response to genotoxic stress.
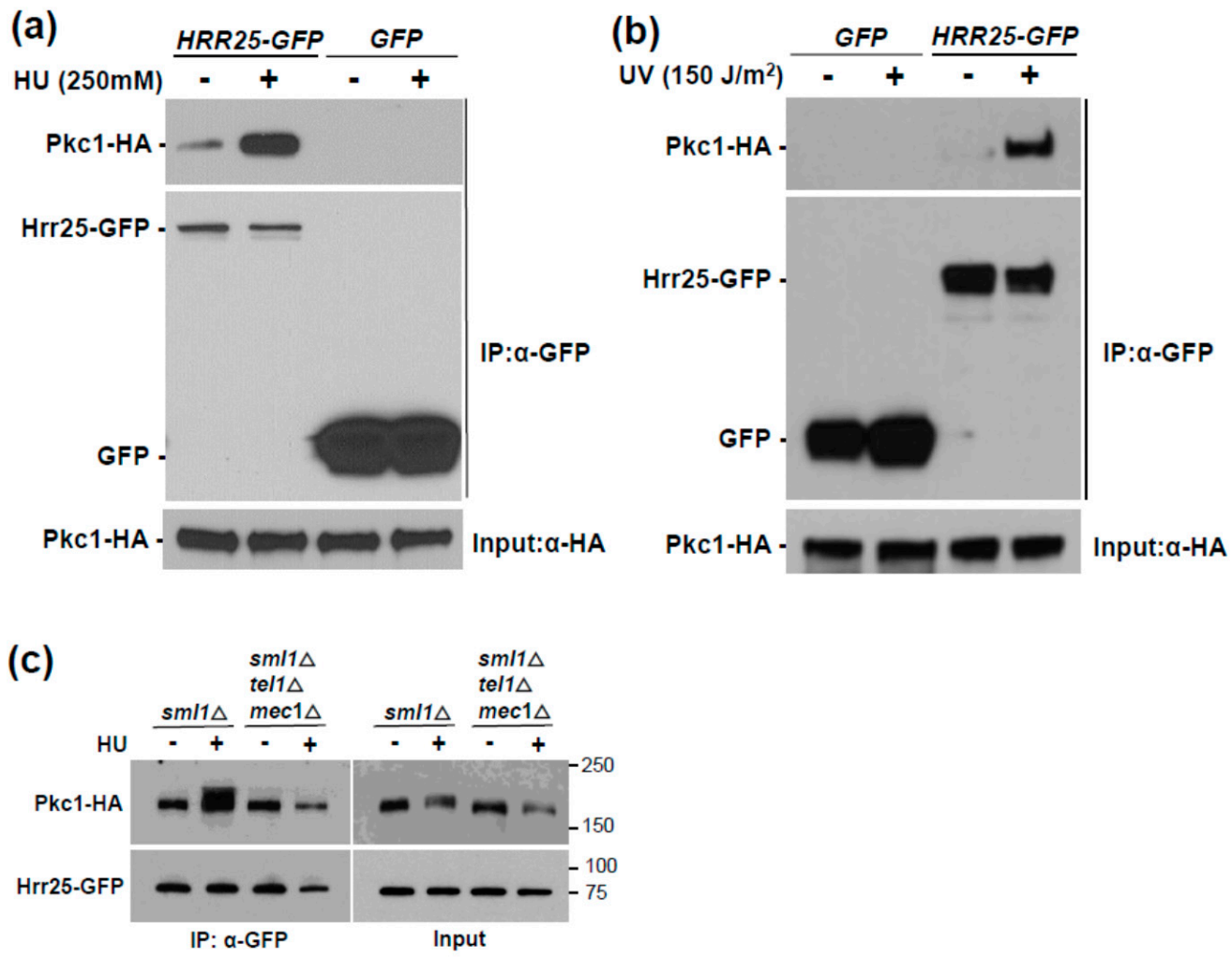

Figure 2. HU treatment induces association of Pkc1 with Hrr25. (a) Wild-type cells (DL100) coexpressing Pkc1-HA (from p813) and Hrr25-GFP (from p3357) or GFP (from p3358) were treated with $250 \mathrm{mM} \mathrm{HU}$ for $4 \mathrm{~h}$. Hrr25-GFP or GFP was immunoprecipitated (IP) from extracts and samples were tested by immunoblot analysis for co-IP of Pkc1-HA. Input Pkc1-HA from extracts is shown at bottom; (b) UV treatment induces association of Pkc1 with Hrr25. Wild-type cells (DL100) co-expressing Pkc1-HA (from p813) and Hrr25-GFP (from p3357) or GFP (from p3358) were treated with UV light $\left(150 \mathrm{~J} / \mathrm{m}^{2}\right)$ and returned to culture for $2 \mathrm{~h}$ post-irradiation prior to extract preparation. Hrr25-GFP or GFP was immunoprecipitated (IP) from extracts and treated as above; (c) MEC1 and TEL1 are required for the HU-induced association of Hrr25 with Pkc1. Cultures co-expressing Pkc1-HA and Hrr25-GFP (from p3562) were treated with HU as above and processed for co-IP of Pkc1-HA with

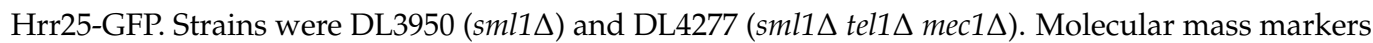
(in $\mathrm{kDa}$ ) are shown on the right.

We next tested the role of Mec1 and Tel1 in the induced association of Hrr25 with Pkc1. Here, we found that, not only are the DNA damage checkpoint kinases required for the Pkc1 phosphorylation band-shift, but they are also required for the induced association of Hrr25 with Pkc1 (Figure 2c), suggesting that Mec1 and Tel1 induce the Pkc1 phosphorylation band-shift indirectly by driving its association with Hrr25. Therefore, we sought to test this idea using mutants in HRR25. Because the HRR25 gene is essential for viability, we constructed two analog-sensitive "gatekeeper" alleles [53] of HRR25

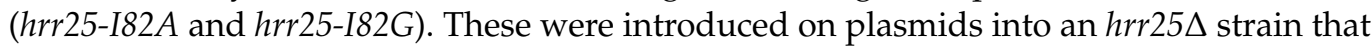
is maintained with a galactose-inducible form of HRR25 and tested for their sensitivity to a collection of protein kinase inhibitory ATP-analogs in glucose-containing medium (YPD). We determined that the hrr25-I82A allele conferred optimum growth sensitivity to PP1 analog IV, which did not appreciably inhibit the growth of the strain expressing wild-type HRR25 (Supplemental Figure S2). We next introduced the hrr25-I82A allele to an hrr25 $\Delta$ strain by plasmid shuffle (See Materials and Methods, Section 2) to test the 
importance of this protein kinase in the HU-induced Pkc1 band-shift. The strain expressing the hrr25-I82A allele along with an epitope tagged form of Pkc1, was subjected to inhibition of Hrr25, together with HU treatment to induce genotoxic stress. Pkc1 failed to display an HU-induced band-shift in the hrr25-I82A strain in the presence of inhibitor, in contrast to the HRR25 strain (Figure 3a). This suggests that Hrr25 catalytic activity is, indeed, required for the Pkc1-bandshift observed in response to genotoxic stress.

(a)

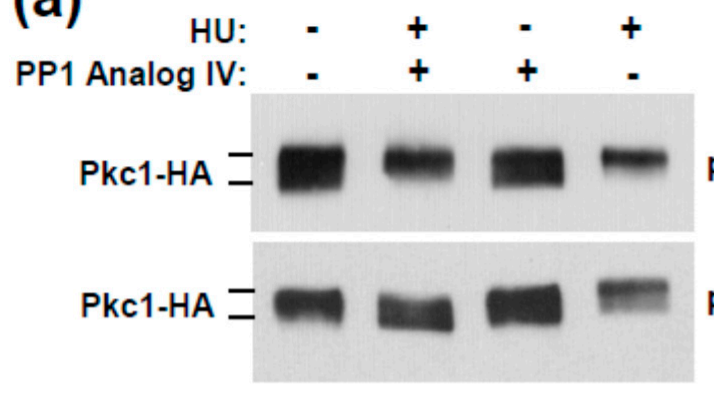

(b)

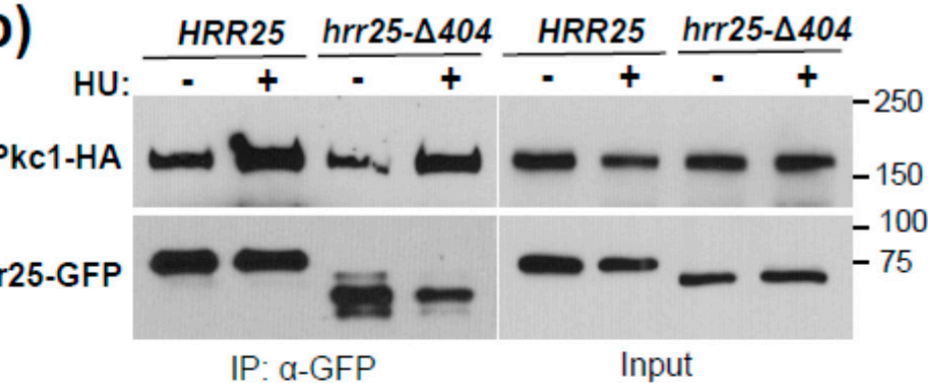

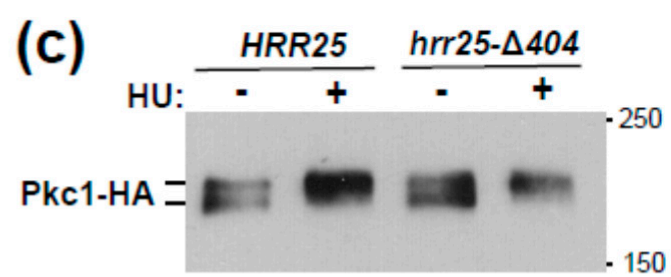

phrr25-182A

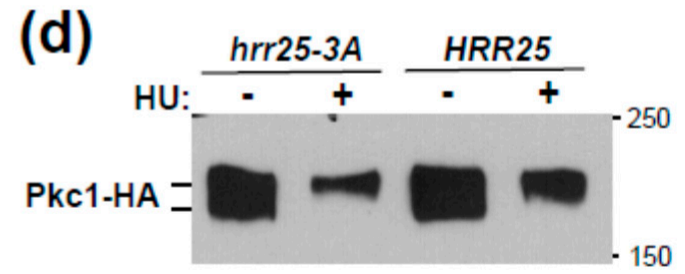

Figure 3. An analog-sensitive form of Hrr25 shows that its catalytic activity is required for the HU-induced Pkc1 band-shift. (a) An hrr25 $\Delta$ strain complemented by plasmid-borne HRR25 (DL4527) or hrr25-182A (DL4528; encoding an analog-sensitive form) and expressing Pkc1-HA (from p813) was treated simultaneously with HU (250 mM) and/or PP1 analog IV (20 $\mu$ M) for $4 \mathrm{~h}$. Extracts were processed for immunoblot analysis of Pkc1-HA; (b) A C-terminal truncation of Hrr25 lacking three potential Mec1/Tel1 phosphorylation sites associates normally with Pkc1. An hrr25 strain complemented by plasmidborne HRR25-GFP (DL4541) or hrr25- 4404 (DL4542) and expressing Pkc1-HA (from p813) was treated with HU (250 mM for $4 \mathrm{~h}$ ). Hrr25-GFP was immunoprecipitated from extracts and tested for co-IP of Pkc1-HA by immunoblot analysis. Molecular mass markers (in kDa) are on the right; (c) A C-terminal truncation of Hrr25 does not impact the HU-induced Pkc1 band-shift. An hrr25 $\Delta$ strain complemented by plasmid-borne HRR25 (DL4527) or hrr25- 4404 (DL4555) and expressing Pkc1-HA was treated with HU as above and processed for immunoblot analysis of Pkc1-HA (d) A mutant form of HRR25 lacking three potential Mec1/Tel1 phosphorylation sites does not impact the HU-induced Pkc1 band-shift. An hrr25 $\Delta$ strain complemented by plasmid-borne HRR25 (DL4527) or hrr25-3A (DL4556) and expressing Pkc1-HA was treated with HU as above and processed for immunoblot analysis of Pkc1-HA.

Hrr25 possesses three potential Mec1/Tel1 sites (S/T-Q) [21], which all reside within the C-terminal tail of Hrr25 (residues S405, S438, and T453). Therefore, we generated a truncated version of Hrr25 that is missing the C-terminal domain from residues 405-494 (hrr25- 4 404), which removes all three potential Mec1/Tel1 sites. This allele complemented the lethality of the hrr $25 \Delta$ mutation, therefore we tested it for HU-induced association with Pkc1 and for the HU-induced Pkc1 band-shift. The truncated form of Hrr25 was recruited normally to $\mathrm{Pkc1}$ in response to HU treatment (Figure $3 \mathrm{~b}$ ) and retained its ability to drive the Pkc1 band-shift (Figure 3c). However, we considered the possibility that the Hrr25 C-terminal region might carry an auto-inhibitory domain, truncation of which could activate Hrr25 independently of Mec1/Tel1. To address this possibility, we mutated the three potential Mec1/Tel1 sites within this domain to Ala residues, yielding hrr25-3A, and tested the influence of this allele on the HU-induced Pkc1 band-shift. As with the truncated allele, the hrr25-3A mutant was able to mediate the HU-induced band-shift normally 
(Figure 3d). Therefore, we conclude that Mec1 and Tel1 likely regulate HU-induced Hrr25 association with $\mathrm{Pkcl}$ and the $\mathrm{Pkcl}$ band-shift by means other than direct phosphorylation of Hrr25. Because neither Rad53, nor Chk1, the known effector kinases of Mec1 and Tel1, were required for the HU-induced $\mathrm{Pkcl}_{\mathrm{k}}$ band-shift, it remains unclear how the sensor kinases regulate the Hrr25 action on Pkc1. It is possible that Mec1 and Tel1 act on Pkc1, rather than on Hrr25, to regulate the association of these protein kinases. Nevertheless, our results strongly suggest that both Hrr25 and Pkc1 are indirect Mec1/Tel1 effectors.

\subsection{Identification of Pkc1 Phospho-Sites in Response to HU Treatment}

Hrr25 is an ortholog of mammalian casein kinase 1 delta (CK1ס) [54]. Two phosphorylation site motifs for this class of protein kinase have been described [55-58]. These protein kinases require either a priming phosphorylation at position -3 relative to the target $\mathrm{S} / \mathrm{T}$ site (i.e., $\mathrm{p}-\mathrm{S} / \mathrm{TXXS} / \mathrm{T}$ ) or an acidic residue at position -3 relative to the target site (i.e., D/EXXS/T).

We conducted both a shotgun mass spectrometric (MS) analysis and a quantitative SILAC MS analysis of HU-induced phosphorylation sites on Pkc1 [43]. These analyses identified many phosphorylation sites on Pkc1, several of which had not been described previously (i.e., T570, T626, S666, T779, S781, and T785; Supplemental Figure S3). Among the phosphorylation sites identified in our SILAC MS experiments, only three appeared to be upregulated in response to HU treatment: S2, S577, and S657 (Supplemental Table S3). Of these, both S577 and S657 are potential Hrr25 phosphorylation sites because S577 has a priming phosphorylation site (p-S574) and S657 is positioned three residues beyond E654 (Figure 4a). Therefore, we started our mutational analysis with these three sites. The individual mutations did not display a detectable impact on the HU-induced Pkc1 bandshift (not shown), so we created a triple mutant. The $p k c 1-3 A$ ( $p k c 1-S 2 A, S 577 A, S 657 A)$ allele was able to complement the lethality of a $p k c 1 \Delta$ mutant for growth on rich medium in the absence of osmotic support. Therefore, we examined its behavior in response to genotoxic stress. The HU-induced $\mathrm{Pkcl}_{\mathrm{k}}$ band-shift was somewhat diminished in the $p k c 1-$ $3 A$ mutant (Figure $4 \mathrm{~b}$ ), revealing a cumulative effect of these phosphorylation sites. We next tested this mutant for its sensitivity to HU and UV treatment. However, this mutant did not display increased sensitivity to either treatment (Figure 4c). Therefore, we considered a larger collection of Pkc1 phosphorylation sites.

Among the phosphorylation sites identified in our analyses, together with those established previously [21,59-61], we identified 13 phosphorylation sites within Pkc1 that fit either of the two CK1 consensus sequences. Figure 4a shows a map of these sites, all of which reside within the $\mathrm{N}$-terminal regulatory domain of Pkc1. However, most of these sites (11) are clustered in an area without recognizable regulatory features between residues 577 and 804 . We mutated all of these phosphorylation sites to alanine residues in groups and in series. We were only able to detect an impact on the HU-induced Pkc1 band-shift once at least nine of these CK1 residues were mutated (data not shown). Blocking the HUinduced band-shift completely required mutation of all 13 sites in the pkc1-S/T13A mutant (Figure 4d). The UV-induced band-shift was also blocked in the pkc1-S/T13A mutant (Figure 4e). The DNA damage checkpoint was activated normally in the pkc1-S/T13A mutant, as judged by a strong Rad53 band-shift (Figure $4 \mathrm{~d}, \mathrm{e}$ ). The $p k c 1-S / T 13 A$ allele also complemented the null mutant for growth in the absence of osmotic support. Therefore, we tested the sensitivity of this strain to genotoxic stress. However, like the $p k c 1-3 A$ mutant, the $p k c 1-S / T 13 A$ mutant did not display enhanced sensitivity to either HU or UV treatment (Figure 4c), suggesting that the biological impact of Pkc1 hyper-phosphorylation during genotoxic stress is too subtle to detect by this viability assay. 
(a)
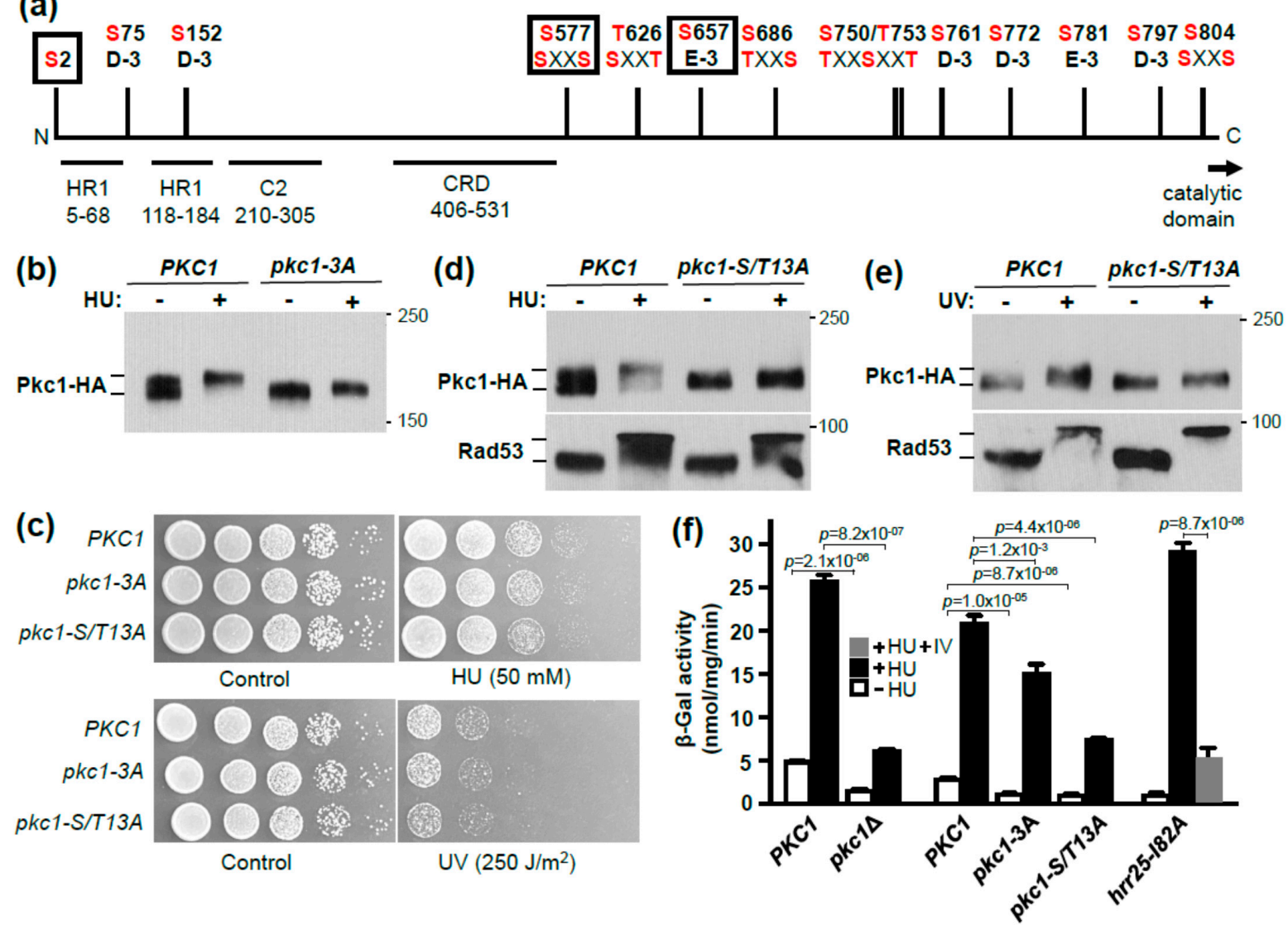

Figure 4. CK1 phosphorylation sites within the Pkc1 regulatory domain are responsible for the genotoxic stress-induced Pkc1 band-shift. (a) Phosphorylation sites within the Pkc1 regulatory domain mutated in this study. Phosphorylated residues are marked in red. The three residues mutated in the $p k c 1-3 A$ allele (S2, S577, and S657) are marked by boxes and were identified by SILAC MS as increased in phosphorylation state in response to HU treatment. Two of these residues (S577 and S657) are within consensus CK1 phosphorylation sites, with either a priming phospho-Ser at position -3 (S577) or an acidic residue (Asp) at position -3 (S657). Other phosphorylated residues that reside within CK1 consensus sites are also indicated and were mutated in the $p k c 1-S / T 13 A$ allele. Known regulatory elements, Rho-binding domains (HR1), calcium/lipid-binding domain (C2), and Cys-rich domain (CRD) are also shown. The catalytic domain is C-terminal to the regulatory domain and starts at residue 824; (b) HU-induced phosphorylation band-shift of the Pkc1-3A mutant. Plasmids were PKC1-HA (p813) and $p k c 1-3 A-H A$ (p3619) (c) The $p k c 1-3 A$ and $p k c 1-S / T 13 A$ mutants do not show increased sensitivity to genotoxic stress. Serial 10-fold dilutions of cultures grown to mid-log phase in YPD were spotted onto plates (left to right) with or without HU. Cultures treated with UV were similarly diluted and spotted onto YPD plates. Plates were incubated at $25{ }^{\circ} \mathrm{C}$ for two days. Plasmids were PKC1-HA (p3623), pkc1-3A (p3624), and pkc1-S/T13A (p3625); (d) HU-induced phosphorylation band-shift of the Pkc1-S/T13A mutant and Rad53. Plasmids were PKC1-HA (p813) pkc1-S/T13A (p3612); (e) UV-induced phosphorylation band-shift of the Pkc1-S/T13A mutant and Rad53. Plasmids were PKC1-HA (p813) and pkc1-S/T13A (p3612). Strain DL1021 ( $p k c 1 \Delta)$ was used for experiments shown in (b,d,e). Strain DL376 ( $p k c 1 \Delta)$ was used for the experiment in panel (c); (f) HU-induced RNR3-lacZ expression is diminished in a $p k c 1 \Delta$ mutant, and in the $p k c 1-3 A$ and pkc1-S/T13A mutants. Strain DL376 (pkc1 1 ) was co-transformed with pRNR3-lacZ (p2947) and PKC1-HA (p3623), pkc1-3A (p3624), pkc1-S/T13A (p3625), or vector alone (p118). Cells were cultured in the presence of $0.5 \mathrm{M}$ sorbitol for osmotic support (pair on left), or in the absence of sorbitol. Cultures were treated for $4 \mathrm{~h}$ with $250 \mathrm{mM} \mathrm{HU}$ and $\beta$-galactosidase activity was measured from extracts. The hrr25-I82A mutant (DL4528; right) was treated with HU plus or minus PP1 analog IV (20 $\mu \mathrm{M})$ for $4 \mathrm{~h}$. Each value is the mean and standard deviation from three independent cultures. Pair-wise $p$-values for HU-treated and untreated samples were calculated using student t-test and were all at least $p \leq 0.00001$, except the HU-treated PKC1 and $p k c 1-3 A$ pair, which was $p=0.0012$. An additional $\mathrm{p}$-value of $p<0.00001$ was obtained for the hrr25-I82A mutant for HU-treated samples, with and without analog IV. 
HRR25 has been implicated in the transcriptional response to DNA damage, most notably in the induction of the RNR3 gene [52], but its role has not been clearly established. The cell cycle transcriptional regulatory factor SBF, comprised of Swi4 and Swi6, is similarly important for this transcriptional response and Hrr25 associates with and phosphorylates Swi6 in vitro [52]. However, RNR3 induction in response to DNA damage was also shown to be largely under the control of the Mec1-Rad53-Dun1 pathway through the Crt1 transcriptional repressor, which is hyper-phosphorylated in response to genotoxic stress [26]. Therefore, we asked if the expression of an RNR3-lacZ reporter was influenced by PKC1. We found that both basal RNR3-lacZ expression and its induction by HU treatment were strongly diminished in a $p k c 1 \Delta$ mutant grown in the presence of osmotic support (Figure 4f). We also examined the effect of the $p k c 1-3 A$ and $p k c 1-S / T 13 A$ alleles. RNR3-lacZ basal expression and induction were only modestly diminished in the $p k c 1-3 A$ mutant, but were more strongly impaired in the $p k c 1-S / T 13 A$ mutant (Figure $4 \mathrm{f}$ ). Although the basal and induced levels of RNR3-lacZ expression were reduced in each of these mutants, the relative induction was retained for all (approximately 6 to 8 -fold). Finally, we tested the analog-sensitive hrr25-I82A mutant for induction of RNR3-lacZ expression and found that, as anticipated, inhibitor treatment strongly diminished $\mathrm{HU}$ induction (Figure $4 \mathrm{f}$ ). These results suggest that Hrr25 may regulate the transcriptional response to DNA damage in part through phosphorylation of Pkc1 (Figure 5). This pathway would be independent of the Mec1-Rad53-Dun1 pathway, because Pkc1 hyper-phosphorylation in response to genotoxic stress does not require Rad53.

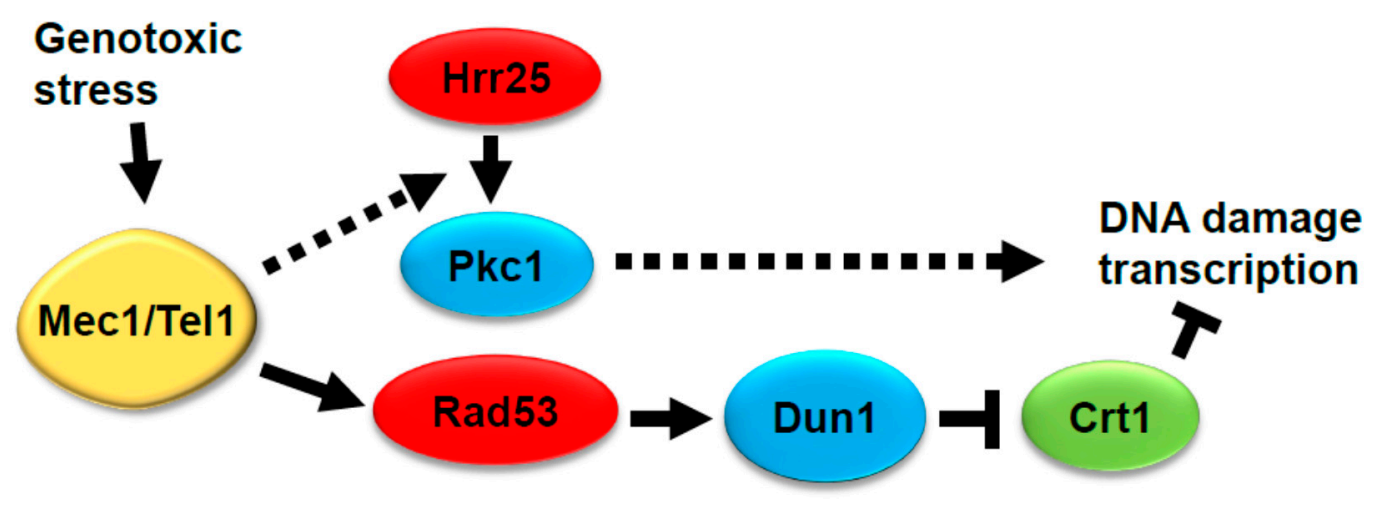

Figure 5. Proposed contribution of Hrr25 and Pkc1 to DNA damage-induced transcription. Pathway from Mec1 and Tel1 through Hrr25 and Pkc1 is added to the pathway established by Huang et al. [26]. Dashed arrows suggest indirect regulation.

\section{Conclusions}

We can draw several conclusions from this study. First, the checkpoint kinases Mec1 and Tel1 regulate hyper-phosphorylation of Pkc1 under conditions of genotoxic stress by inducing the association of CK1 homolog Hrr25 with Pkc1. This happens through a mechanism that does not require the phosphorylation of Hrr25 by Mec1 or Tel1 and suggests that Hrr25 and Pkc1 are indirect effectors of the checkpoint kinases. Second, a large collection of CK1 phosphorylation sites contribute to the genotoxic stress-induced Pkc1 band-shift. Finally, CK1 phosphorylation site mutants in Pkc1 are partially deficient in RNR3-lacZ basal and DNA damage-induced expression, suggesting that Pkc1 hyperphosphorylation by Hrr 25 contributes to this response.

Supplementary Materials: The following are available online at https:/ / www.mdpi.com/article/10 .3390/jof7100874/s1, Table S1: Pkc1 MS with HU only, Table S2: Pkc1 MS without HU only, Table S3: SILAC MS Pkc1 with and without HU, Figure S1: Binding of Hrr25 to Pkc1. Figure S2: Sensitivity of hrr 25 "gatekeeper" mutants to growth inhibition by inhibitory ATP analogs, Figure S3: Pkc1 phosphorylation sites identified in this study. 
Author Contributions: D.E.L., L.L., W.R. and E.M. contributed to the design of the experimental approach and the interpretation of data. Conceptualization, D.E.L. and W.R.; Methodology, D.E.L., L.L., W.R., G.A. and E.M.; Software, J.V., W.R. and E.M.; Validation and Formal Analysis, D.E.L., L.L., W.R. and E.M.; Data Curation, L.L., J.V. and E.M.; Writing-Original Draft Preparation, D.E.L., L.L., W.R. and E.M.; Writing-Review \& Editing, L.L., J.V., W.R., E.M., C.E.C., J.C.S., G.A. and D.E.L.; Supervision, Project Administration, and Funding Acquisition, D.E.L., G.A., C.E.C. and J.C.S. All authors have read and agreed to the published version of the manuscript.

Funding: This work was supported by grants from the NIH (R01 GM48533 to DEL; R01 GM129324 to JCS; and R24 GM134210 and S10 RR020946 to CEC). GA, JV, and WR were supported by the FWF Austrian Science Fund Special Research Program F34.

Data Availability Statement: The MS phospho-proteomics data have been deposited at the zenodo repository (https:/ / zenodo.org/ accessed on 10 September 2021) and can be accessed via 10.5281/ zenodo.5102666.

Acknowledgments: We thank David Hollenstein for general MS-related support, and Martha Cyert, Scott Emr, Juan Carlos Igual, Marcus Smolka, Stephen Elledge, and Gerhard Paravicini for yeast strains and plasmids.

Conflicts of Interest: The authors declare no conflict of interests. The funders had no role in the design of the study; in the collection, analyses, or interpretation of data; in the writing of the manuscript, or in the decision to publish the results.

\section{References}

1. Klis, F.M.; Mol, P.; Hellingwerf, K.; Brul, S. Dynamics of cell wall structure in Saccharomyces cerevisiae. FEMS Microbiol. Rev. 2002, 26, 239-256. [CrossRef]

2. Levin, D.E. Cell Wall Integrity Signaling in Saccharomyces cerevisiae. Microbiol. Mol. Biol. Rev. 2005, 69, 262-291. [CrossRef]

3. Levin, D.E. Regulation of cell wall biosynthesis in Saccharomyces cerevisiae: The cell wall integrity signaling pathway. Genetics 2011, 189, 1145-1175. [CrossRef]

4. Lesage, G.; Bussey, H. Cell Wall Assembly in Saccharomyces cerevisiae. Microbiol. Mol. Biol. Rev. 2006, 70, 317-343. [CrossRef] [PubMed]

5. Jung, U.S.; Levin, D. Genome-wide analysis of gene expression regulated by the yeast cell wall integrity signalling pathway. Mol. Microbiol. 1999, 34, 1049-1057. [CrossRef] [PubMed]

6. $\quad$ Roberts, C.J.; Nelson, B.; Marton, M.J.; Stoughton, R.; Meyer, M.R.; Bennett, H.A.; He, Y.D.; Dai, H.; Walker, W.L.; Hughes, T.R.; et al. Signaling and Circuitry of Multiple MAPK Pathways Revealed by a Matrix of Global Gene Expression Profiles. Science 2000, 287, 873-880. [CrossRef] [PubMed]

7. Jung, U.S.; Sobering, A.K.; Romeo, M.J.; Levin, D.E. Regulation of the yeast Rlm1 transcription factor by the Mpk1 cell wall integrity MAP kinase. Mol. Microbiol. 2002, 46, 781-789. [CrossRef] [PubMed]

8. Garcia, R.; Bermejo, C.; Grau, C.; Pérez, R.; Peña, J.M.R.; François, J.M.; Nombela, C.; Arroyo, J. The Global Transcriptional Response to Transient Cell Wall Damage in Saccharomyces cerevisiae and Its Regulation by the Cell Integrity Signaling Pathway. J. Biol. Chem. 2004, 279, 15183-15195. [CrossRef]

9. Boorsma, A.; De Nobel, H.; Ter Riet, B.; Bargmann, B.; Brul, S.; Hellingwerf, K.J.; Klis, F.M. Characterization of the transcriptional response to cell wall stress in Saccharomyces cerevisiae. Yeast 2004, 21, 413-427. [CrossRef] [PubMed]

10. Dodou, E.; Treisman, R. The Saccharomyces cerevisiae MADS-box transcription factor Rlm1 is a target for the Mpk1 mitogenactivated protein kinase pathway. Mol. Cell. Biol. 1997, 17, 1848-1859. [CrossRef]

11. Watanabe, Y.; Takaesu, G.; Hagiwara, M.; Irie, K.; Matsumoto, K. Characterization of a serum response factor-like protein in Saccharomyces cerevisiae, Rlm1, which has transcriptional activity regulated by the Mpk1 (Slt2) mitogen-activated protein kinase pathway. Mol. Cell. Biol. 1997, 17, 2615-2623. [CrossRef]

12. Madden, K.; Sheu, Y.-J.; Baetz, K.; Andrews, B.; Snyder, M. SBF Cell Cycle Regulator as a Target of the Yeast PKC-MAP Kinase Pathway. Science 1997, 275, 1781-1784. [CrossRef]

13. Baetz, K.; Moffat, J.; Haynes, J.; Chang, M.; Andrews, B. Transcriptional Coregulation by the Cell Integrity Mitogen-Activated Protein Kinase Slt2 and the Cell Cycle Regulator Swi4. Mol. Cell. Biol. 2001, 21, 6515-6528. [CrossRef] [PubMed]

14. Kim, K.Y.; Truman, A.W.; Levin, D.E. Yeast Mpk1 mitogen-activated protein kinase activates transcription through Swi4/Swi6 by a non-catalytic mechanism that requires upstream signal. Mol. Cell. Biol. 2008, 28, 2579-2589. [CrossRef]

15. Kim, K.-Y.; Levin, D.E. Mpk1 MAPK Association with the Paf1 Complex Blocks Sen1-Mediated Premature Transcription Termination. Cell 2011, 144, 745-756. [CrossRef] [PubMed]

16. LeDuc, A.; He, C.H.; Ramotar, D. Disruption of the Saccharomyces cerevisiae cell-wall pathway gene SLG1 causes hypersensitivity to the antitumor drug bleomycin. Mol. Genet. Genom. 2003, 269, 78-89. [CrossRef] [PubMed]

17. Queralt, E.; Igual, J.C. Functional Connection Between the Clb5 Cyclin, the Protein Kinase C Pathway and the Swi4 Transcription Factor in Saccharomyces cerevisiae. Genetics 2005, 171, 1485-1498. [CrossRef] 
18. Zu, T.; Verna, J.; Ballester, R. Mutations in WSC genes for putative stress receptors result in sensitivity to multiple stress conditions and impairment of Rlm1-dependent gene expression in Saccharomyces cerevisiae. Mol. Genet. Genom. 2001, 266, 142-155. [CrossRef] [PubMed]

19. Soriano-Carot, M.; Bañó, M.C.; Igual, J.C. The yeast mitogen-activated protein kinase Slt2 is involved in the cellular response to genotoxic stress. Cell Div. 2012, 7, 1. [CrossRef]

20. Jiménez-Gutiérrez, E.; Alegría-Carrasco, E.; Sellers-Moya, A.; Molina, M.; Martín, H. Not just the wall: The other ways to turn the yeast CWI pathway on. Int. Microbiol. 2020, 23, 107-119. [CrossRef]

21. Albuquerque, C.P.; Smolka, M.B.; Payne, S.; Bafna, V.; Eng, J.; Zhou, H. A Multidimensional Chromatography Technology for In-depth Phosphoproteome Analysis. Mol. Cell. Proteom. 2008, 7, 1389-1396. [CrossRef]

22. Truman, A.; Kim, K.-Y.; Levin, D.E. Mechanism of Mpk1 Mitogen-Activated Protein Kinase Binding to the Swi4 Transcription Factor and Its Regulation by a Novel Caffeine-Induced Phosphorylation. Mol. Cell. Biol. 2009, 29, 6449-6461. [CrossRef]

23. Gobbini, E.; Cesena, D.; Galbiati, A.; Lockhart, A.; Longhese, M.P. Interplays between ATM/Tel1 and ATR/Mec1 in sensing and signaling DNA double-strand breaks. DNA Repair 2013, 12, 791-799. [CrossRef] [PubMed]

24. Nakada, D.; Shimomura, T.; Matsumoto, K.; Sugimoto, K. The ATM-related Tel1 protein of Saccharomyces cerevisiae controls a checkpoint response following phleomycin treatment. Nucleic Acids Res. 2003, 31, 1715-1724. [CrossRef] [PubMed]

25. Zou, L.; Elledge, S.J. Sensing DNA Damage Through ATRIP Recognition of RPA-ssDNA Complexes. Science 2003, $300,1542-1548$. [CrossRef] [PubMed]

26. Huang, M.; Zhou, Z.; Elledge, S.J. The DNA Replication and Damage Checkpoint Pathways Induce Transcription by Inhibition of the Crt1 Repressor. Cell 1998, 94, 595-605. [CrossRef]

27. Melo, J.; Toczyski, D. A unified view of the DNA-damage checkpoint. Curr. Opin. Cell Biol. 2002, 14, 237-245. [CrossRef]

28. Sidorova, J.M.; Breeden, L.L. Precocious G1/S transitions and genomic instability: The origin connection. Mutat. Res. 2003, 532, 5-19. [CrossRef]

29. Liang, F.; Wang, Y. DNA Damage Checkpoints Inhibit Mitotic Exit by Two Different Mechanisms. Mol. Cell. Biol. 2007, 27, 5067-5078. [CrossRef] [PubMed]

30. Soriano-Carot, M.; Quilis, I.; Bañó, C.; Igual, J.C. Protein kinase C controls activation of the DNA integrity checkpoint. Nucleic Acids Res. 2014, 42, 7084-7095. [CrossRef]

31. Liu, L.; Levin, D.E. Intracellular mechanism by which genotoxic stress activates yeast SAPK Mpk1. Mol. Biol. Cell 2018, 29, 2898-2909. [CrossRef] [PubMed]

32. Huang, K.N.; Symington, L.S. Mutation of the gene encoding protein kinase C 1 stimulates mitotic recombination in Saccharomyces cerevisiae. Mol. Cell. Biol. 1994, 14, 6039-6045. [CrossRef]

33. Li, X.; Heyer, W.-D. Homologous recombination in DNA repair and DNA damage tolerance. Cell Res. 2008, 18, 99-113. [CrossRef]

34. Yang, W.-L.; Bruno, M.E.C.; Carman, G.M. Regulation of Yeast CTP Synthetase Activity by Protein Kinase C. J. Biol. Chem. 1996, 271, 11113-11119. [CrossRef]

35. Lee, J.; Liu, L.; Levin, D.E. Stressing out or stressing in: Intracellular pathways for SAPK activation. Curr. Genet. 2019, 65, 417-421. [CrossRef]

36. Siliciano, P.G.; Tatchell, K. Transcription and regulatory signals at the mating type locus in yeast. Cell 1984, 37, 969-978. [CrossRef]

37. Kafadar, K.A.; Zhu, H.; Snyder, M.; Cyert, M.S. Negative regulation of calcineurin signaling by Hrr25p, a yeast homolog of casein kinase I. Genes Dev. 2003, 17, 2698-2708. [CrossRef]

38. Gietz, R.D.; Schiestl, R.H.; Willems, A.R.; Woods, R.A. Studies on the transformation of intact yeast cells by the LiAc/SSDNA/PEG procedure. Yeast 1995, 11, 355-360. [CrossRef]

39. Sikorski, R.S.; Hieter, P. A system of shuttle vectors and yeast host strains designed for efficient manipulation of DNA in Saccharomyces cerevisiae. Genetics 1989, 122, 19-27. [CrossRef]

40. Hill, J.E.; Myers, A.; Koerner, T.J.; Tzagoloff, A. Yeast/E. coli shuttle vectors with multiple unique restriction sites. Yeast 1986, 2, 163-167. [CrossRef] [PubMed]

41. Denis, V.; Cyert, M.S. Molecular Analysis Reveals Localization of Saccharomyces cerevisiae Protein Kinase C to Sites of Polarized Growth and Pkc1p Targeting to the Nucleus and Mitotic Spindle. Eukaryot. Cell 2005, 4, 36-45. [CrossRef] [PubMed]

42. Lee, J.; Reiter, W.; Dohnal, I.; Gregori, C.; Beese-Sims, S.; Kuchler, K.; Ammerer, G.; Levin, D.E. MAPK Hog1 closes the S. cerevisiae glycerol channel Fps1 by phosphorylating and displacing its positive regulators. Genes Dev. 2013, 27, 2590-2601. [CrossRef] [PubMed]

43. Reiter, W.; Anrather, R.; Dohnal, I.; Pichler, P.; Veis, J.; Grøtli, M.; Posas, F.; Ammerer, G. Validation of regulated protein phosphorylation events in yeast by quantitative mass spectrometry analysis of purified proteins. Proteomics 2012, 12, 3030-3043. [CrossRef]

44. Kamada, Y.; Jung, U.S.; Piotrowski, J.; Levin, D. The protein kinase C-activated MAP kinase pathway of Saccharomyces cerevisiae mediates a novel aspect of the heat shock response. Genes Dev. 1995, 9, 1559-1571. [CrossRef] [PubMed]

45. Kushnirov, V.V. Rapid and reliable protein extraction from yeast. Yeast 2000, 16, 857-860. [CrossRef]

46. Zhao, C.; Jung, U.S.; Garrett-Engele, P.; Roe, T.; Cyert, M.S.; Levin, D.E. Temperature-Induced Expression of Yeast FKS2 Is under the Dual Control of Protein Kinase C and Calcineurin. Mol. Cell. Biol. 1998, 18, 1013-1022. [CrossRef] 
47. Ong, S.-E.; Blagoev, B.; Kratchmarova, I.; Kristensen, D.B.; Steen, H.; Pandey, A.; Mann, M. Stable Isotope Labeling by Amino Acids in Cell Culture, SILAC, as a Simple and Accurate Approach to Expression Proteomics. Mol. Cell. Proteom. 2002, 1, $376-386$. [CrossRef] [PubMed]

48. Cox, J.; Mann, M. MaxQuant enables high peptide identification rates, individualized p.p.b.-range mass accuracies and proteomewide protein quantification. Nat. Biotechnol. 2008, 26, 1367-1372. [CrossRef]

49. Nyberg, K.A.; Michelson, R.J.; Putnam, C.W.; Weinert, T.A. Toward Maintaining the Genome: DNA Damage and Replication Checkpoints. Annu. Rev. Genet. 2002, 36, 617-656. [CrossRef]

50. Harper, J.W.; Elledge, S.J. The DNA Damage Response: Ten Years After. Mol. Cell 2007, 28, 739-745. [CrossRef]

51. Hoekstra, M.F.; Liskay, R.M.; Ou, A.C.; DeMaggio, A.J.; Burbee, D.G.; Heffron, F. HRR25, a putative protein kinase from budding yeast: Association with repair of damaged DNA. Science 1991, 253, 1031-1034. [CrossRef] [PubMed]

52. Ho, Y.; Mason, S.; Kobayashi, R.; Hoekstra, M.; Andrews, B. Role of the casein kinase I isoform, Hrr25, and the cell cycle-regulatory transcription factor, SBF, in the transcriptional response to DNA damage in Saccharomyces cerevisiae. Proc. Natl. Acad. Sci. USA 1997, 94, 581-586. [CrossRef] [PubMed]

53. Lopez, M.S.; Kliegman, J.I.; Shokat, K.M. The Logic and Design of Analog-Sensitive Kinases and Their Small Molecule Inhibitors. Methods Enz. 2014, 548, 189-213. [CrossRef]

54. Peng, Y.; Grassart, A.; Lu, R.; Wong, C.C.; Yates, J.; Barnes, G.; Drubin, D.G. Casein Kinase 1 Promotes Initiation of ClathrinMediated Endocytosis. Dev. Cell 2015, 32, 231-240. [CrossRef] [PubMed]

55. Flotow, H.; Roach, P.J. Synergistic phosphorylation of rabbit muscle glycogen synthase by cyclic AMP-dependent protein kinase and casein kinase I. Implications for hormonal regulation of glycogen synthase. J. Biol. Chem. 1989, 264, 9126-9128. [CrossRef]

56. Flotow, H.; Roach, P.J. Role of acidic residues as substrate determinants for casein kinase I. Role of acidic residues as substrate determinants for casein kinase I. J. Biol. Chem. 1991, 266, 3724-3727. [CrossRef]

57. Flotow, H.; Graves, P.; Wang, A.; Fiol, C.; Roeske, R.; Roach, P. Phosphate groups as substrate determinants for casein kinase I action. J. Biol. Chem. 1990, 265, 14264-14269. [CrossRef]

58. Pulgar, V.; Marin, O.; Meggio, F.; Allende, C.C.; Allende, J.E.; Pinna, L.A. Optimal sequences for non-phosphate-directed phoshorylation by protein kinase CK1 (casein kinase-1)—A re-evaluation. Eur. J. Biochem. 1999, 260, 520-526. [CrossRef]

59. Swaney, D.L.; Beltrao, P.; Starita, L.; Guo, A.; Rush, J.; Fields, S.; Krogan, N.J.; Villen, J. Global analysis of phosphorylation and ubiquitylation cross-talk in protein degradation. Nat. Methods 2013, 10, 676-682. [CrossRef]

60. MacGilvray, M.E.; Shishkova, E.; Place, M.; Wagner, E.R.; Coon, J.J.; Gasch, A.P. Phosphoproteome Response to Dithiothreitol Reveals Unique Versus Shared Features of Saccharomyces cerevisiae Stress Responses. J. Proteome Res. 2020, 19, 3405-3417. [CrossRef]

61. Lanz, M.C.; Yugandhar, K.; Gupta, S.; Sanford, E.J.; Faça, V.M.; Vega, S.; Joiner, A.M.N.; Fromme, J.C.; Yu, H.; Smolka, M.B. In-depth and 3-dimensional exploration of the budding yeast phosphoproteome. EMBO Rep. 2021, 22, e51121. [CrossRef] [PubMed] 